\title{
Nutrition and health in women, children, and adolescent girls
}

\author{
Urg. Cution is needed to tackle malnutrition in all forms and to help nutrition unlock \\ the crossiark
}

\section{Francesco Branca and colleagues}

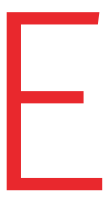

very year the lives of around 50 million children are put at risk because they are dangerously thin from acute undernutrition, while the long term health of more than 40 million children is threatened because they are overweight. Two billion people suffer from vitamin and mineral deficiencies, but overweight and obesity are key contributors to the non-communicable diseases that account for almost two thirds (63\%) of adult deaths globally. These different forms of malnutrition-undernutrition, overweight and obesity, and micronutrient deficienciesnow affect people across the same communities and harm people of all ages. (Unless otherwise cited, the figures given are WHO estimates.)

Improving nutrition therefore presents a key opportunity to improve health. As the UN secretary general launches his second Global Strategy for Women's, Children's and Adolescents' Health in September 2015 a strengthened focus on nutrition is warranted, with special attention to the first 1000 days of life (from pregnancy to the child's second birthday), pregnant and lactating women, women of reproductive age, and adolescent girls.

\section{KEY MESSAGES}

Investment in nutrition is crucial to future efforts to improve the health of women, children, and adolescents; the potential human, societal, and economic gains from such investment are substantial.

Clear global commitments to action are in place, backed by targets to measure progress. All contributors, across government and society, must come together to turn these commitments into action

Specific actions are needed to improve the quality of the diet; to protect, promote and support breast feeding; to ensure that everyone has access to essential nutrition actions; to provide adequate water and sanitation; and to provide information and education.

\section{Methods}

This paper highlights nutrition related priority actions to improve the health of women, children, and adolescent girls. It is based on existing policy guidance issued by the World Health Assembly in the form of resolutions or targets; guidelines from the World Health Organization; or the outcome documents of the Second International Conference on Nutrition (ICN2).

The vast majority of the recommended actions proposed in this paper were agreed by the 162 member states attending the ICN2 in Rome in November 2014. ${ }^{1}$ These recommendations were developed by the secretariats of the Food and Agriculture Organization of the United Nations and WHO on the basis of current evidence and were subject to extensive consultation. An information note on the ICN2 provides more background information on the recommended actions. ${ }^{2}$

Some additional recommendations, specific to women's, children's, or adolescents' nutrition, are based on WHO guidance. Where such a recommendation does not exist, emerging evidence reviewed by the authors is cited.

\section{Problems associated with poor nutrition}

Good nutrition is fundamental for optimal health and growth. Through its effect on health and cognitive development it is also vital for academic performance and productivity, and therefore for healthy economies and socioeconomic development.

\section{Health effects of malnutrition}

The consequences of malnutrition could hardly be more serious: around $45 \%$ of child deaths in 2011 were due to malnutrition (including fetal growth restriction, subopti- mal breast feeding, stunting, wasting, and deficiencies of vitamin A and zinc). In 2013 the growth of around 161 million children aged under 5 was stunted by chronic undernutrition, leading to hampered cognitive and physical development, poor health, and an increased risk of degenerative diseases. ${ }^{3}$ In the same year 51 million children were wasted (having low weight for height) because of acute undernutrition; severe wasting increases the risk of morbidity, particularly from infectious diseases such as diarrhoea, pneumonia, and measles, and is responsible for as many as two million deaths a year. ${ }^{4}$

Meanwhile, deficiencies of vitamin A and zinc cause many deaths (157000 and 116000 child deaths, respectively, in 2011), ${ }^{5}$ and iodine and iron deficiencies, along with stunting, contribute to children not achieving their full potential. Iron and calcium deficiencies increase the risks associated with pregnancy, particularly maternal mortality. ${ }^{5}$

At the same time overweight and obesity in children and adults have been increasing rapidly in all regions of the world, and half a billion adults were affected by obesity in 2010. Dietary risk factors, together with inadequate physical activity, were responsible for $10 \%$ of the global burden of disease and disability in $2010 .^{6}$

\section{Socioeconomic impact of malnutrition}

Malnutrition contributes to an estimated 200 million children failing to attain their full development potential. Stunting is estimated to reduce a country's gross domestic product by as much as $3 \%,{ }^{7}$ and eliminating anaemia could increase adult productivity by $5-17 \% .^{8}$

\section{BOX: NUTRITION IN RECENT GLOBAL INITIATIVES AND COMMITMENTS}

- Global Strategy for Women's and Children's Health: the UN secretary general's strategy, put into action by the global Every Woman Every Child movement, clearly set out the need to tackle nutrition in young children. ${ }^{11}$

- Global nutrition targets for 2025: countries are working towards six global targets agreed at the 65 th World Health Assembly in 2012 (table 1).

- Global Action Plan for the Prevention and Control of Non-communicable Diseases 2013-20: includes targets to reduce salt intake by a third and to halt the increase in obesity among adolescents and adults.

- Second International Conference on Nutrition: in November 2014 the world's leaders committed to eradicating hunger and preventing all forms of malnutrition worldwide. ${ }^{12}$ 


\section{BOX: WHAT DO WE MEAN BY MALNUTRITION?}

- Malnutrition: nutritional disorders in all of their forms (including imbalances in energy intake, macronutrient and micronutrient deficiencies, and unhealthy dietary patterns). Conventionally, the emphasis has been on inadequacy, but malnutrition also applies to excess and imbalanced intakes.

- Overweight: a situation caused by an excessive, unbalanced intake of energy or nutritional substances (and often combined with a sedentary lifestyle).

- Stunting: low height for age (more than two standard deviations below the WHO child growth standard median for children under 5). Stunting is defined by WHO as a public health problem when $20 \%$ or more of the population are affected.

- Undernutrition: a situation in which the body's energy and nutrient requirements are not met because of under-consumption or the impaired absorption and use of nutrients. Undernutrition commonly refers to a deficit in energy intake, but it can also refer to deficiencies of macronutrients and micronutrients, and it can be either acute or chronic.

- Wasting: low weight for height (more than two standard deviations below the WHO child growth standard median for children under 5). Wasting becomes a public health problem when $5 \%$ or more of the population are affected.

Every $\$ 1$ (£0.64; €0.91) invested in tackling undernutrition is estimated to yield around $\$ 18$ in return-the median benefit:cost ratio from a study modelling the effect of preventing one third of stunting in children up to age 3 in 17 high burden countries. ${ }^{9}$ More specifically, a recent study of the benefit:cost ratio of a package of nutrition interventions aimed at averting stunting in 15 countries found that benefits outweighed costs by as much as 42:1, depending on the existing economic and nutritional situation. ${ }^{10}$

\section{What progress has been made in tackling malnutrition?}

Better understanding of the challenges and solutions

The root causes of malnutrition and the factors leading to it are complex and multidimensional. Poverty, underdevelopment, and low socioeconomic status are major contributors, along with other social determinants. Current food systems struggle to provide adequate, safe, and diversified foods. The reasons include constraints on access to land, water, and other resources-often aggravated by environmental damage- along with unsustainable production and consumption patterns, food losses and waste, and unequal distribution and access. Malnutrition is often aggravated by poor feeding and care practices for infants and young children, as well as poor sanitation and hygiene. A lack of access to education, quality health systems, and safe drinking water can also have a negative effect, along with infectious disease and the ingestion of harmful contaminants.

In recent years progress has been made in developing knowledge and understanding of the magnitude and scope of nutritional challenges, the increasing contribution of non-communicable diseases, and the complex web of factors that can influence nutrition.

A greater understanding has developed regarding the importance of nutrition at different stages of the life course and the effect of poor nutrition across generations (fig 1). An intergenerational cycle of malnutrition exists whereby a woman who has anaemia, for example, is likely to have a baby with a reduced birth weight. Low birthweight babies are more likely to be wasted or

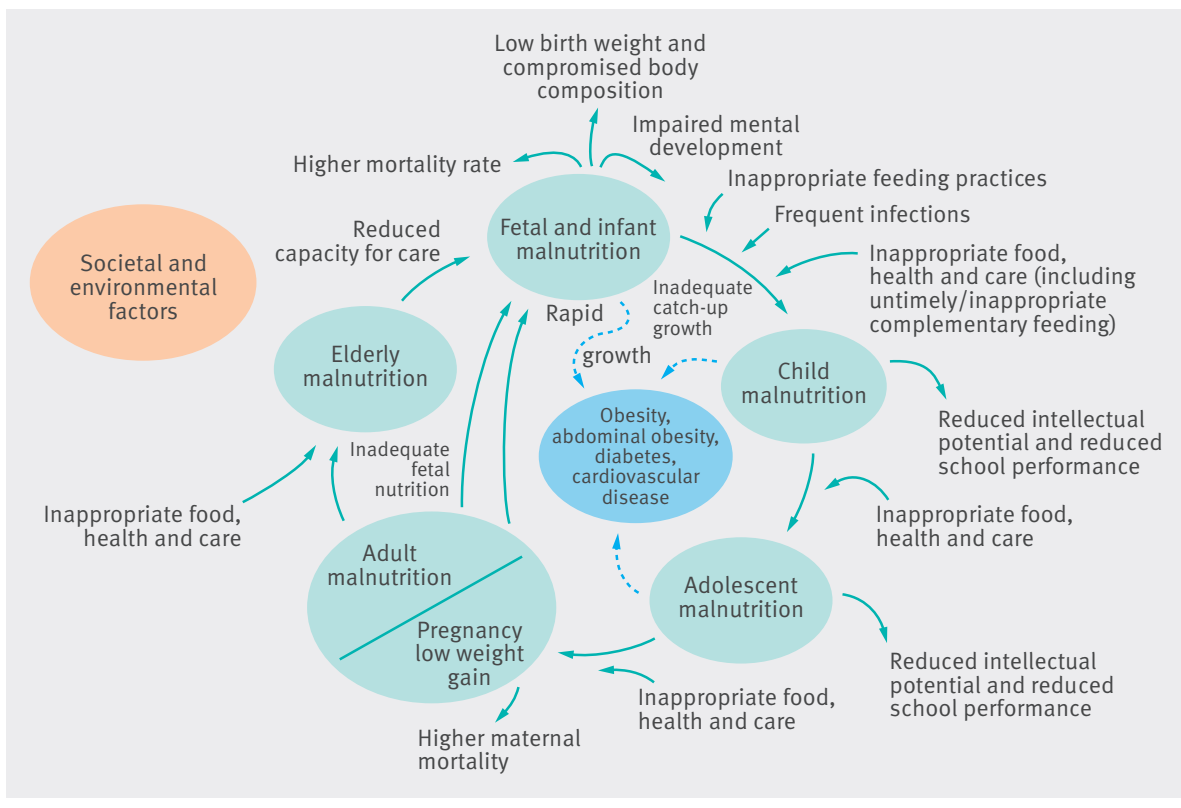

Fig 1 | Nutrition through the life course-proposed causal links ${ }^{13}$

Reproduced from WHO childhood overweight policy brief, based on figure from Darnton-Hill I, Nishida C, James WPT. A life course approach to diet, nutrition and the prevention of chronic diseases. Public Health Nutr 2004;7:101-21. stunted and to have a higher risk of morbidity and mortality and of developing non-communicable diseases later in life. Conversely, if the mother is obese when she starts her pregnancy she is also at increased risk of complications during pregnancy or delivery, which could result in premature delivery-and, therefore, a low birth weight for her baby. Alternatively, if she carries the baby to full term, her baby is more likely to have a higher birth weight and a higher risk of child and adolescent obesity.

The past two decades have also seen a major shift in understanding of the policy responses required to improve nutrition and promote healthy diets. It is now clear that an enabling environment plays a key role and that policies that change aspects of the food environment are required (such as what foods are available, what levels of fat, sugar, or salt they contain, or how much they cost), as well as nutrition education and information.

Similarly, there is now much greater awareness that effective responses need to come from beyond the health sector and that this must involve other sectors, such as those related to water and sanitation, education, trade, and social protection. Crucially, a radical transformation is needed so that food systems can ensure that everyone has access to a sustainable, balanced, and healthy diet.

\section{Progress towards global nutrition targets} Significant progress has been made in reducing hunger and undernutrition in the past two decades: the percentage of people in developing regions experiencing hunger fell from $24 \%$ in $1990-92$ to $14 \%$ in $2011-13 .{ }^{14}$ The 2014 Global Nutrition Report showed, however, that the world is not on track to meet any of the six World Health Assembly nutrition targets (table 1).

\section{What are the priorities for improving nutrition?}

Improving women's, children's, and adolescents' nutrition requires a range of policies, programmes, and interventions at different stages of life. And, since we know that malnourished women give birth to malnourished children, it is possible to take action to improve nutrition across generations (fig 2). 


\begin{tabular}{|c|c|c|c|c|c|c|}
\hline Category & WHA target & $\begin{array}{l}\text { Baseline } \\
\text { years }\end{array}$ & $\begin{array}{l}\text { Baseline } \\
\text { status }\end{array}$ & Target for 2025 & $\begin{array}{l}\text { Globally } \\
\text { on course? }\end{array}$ & Comments \\
\hline Stunting & $\begin{array}{l}40 \% \text { reduction in number of children under } 5 \\
\text { who are stunted* }\end{array}$ & 2012 & 162 million & $\begin{array}{l}\sim 100 \text { million } \\
(\sim 15 \% \text { prevalence })\end{array}$ & No & $\begin{array}{l}\text { Current pace projects } 130 \text { million by } \\
2025 \text { (20\% reduction) }\end{array}$ \\
\hline Anaemia & $\begin{array}{l}50 \% \text { reduction of anaemia in women of } \\
\text { reproductive age }\end{array}$ & 2011 & $29 \%$ & $15 \%$ & No & Very little movement (was $32 \%$ in 2000) \\
\hline Low birth weight & $30 \%$ reduction in low birth weight & $2008-12$ & $15 \%$ & $10 \%$ & No & Little progress to date \\
\hline Under 5 overweight & No increase in childhood overweight & 2012 & $7 \%$ & $7 \%$ & No & Upward trajectory is unchecked \\
\hline Under 5 overweight & $\begin{array}{l}\text { Increase the rate of exclusive breast feeding in } \\
\text { first six months to at least } 50 \%\end{array}$ & $2008-12$ & $38 \%$ & $50 \%$ & No & Rate was $37 \%$ in $2000,41 \%$ in 2012 \\
\hline Wasting & $\begin{array}{l}\text { Reduce and maintain childhood wasting to } \\
\text { under } 5 \%\end{array}$ & 2012 & $8 \%$ & $<5 \%$ & No & No progress (was $8 \%$ globally in 2013) \\
\hline
\end{tabular}

Table 2 | Recommended actions to improve adolescents' nutrition

\section{Recommendations and actions}

Who needs to take action?

Improve maternal nutrition and health

Establish policies and strengthen interventions to ensure that pregnant and

lactating adolescent mothers are adequately nourished

Introduce measures to prevent adolescent pregnancy and to encourage pregnancy National policy makers, health service providers, education sector spacing

\section{Prevent and control anaemia}

Promote healthy and diversified diets containing adequate amounts of bioavailable National policy makers, food and agriculture sectors, health and education sectors iron

Promote consumption of nutrient dense foods, especially foods rich in iron National policy makers, health and education, food and agriculture sectors

Where necessary, implement supplementation strategies and consider fortification National policy makers, food and agriculture sectors

of wheat and maize flours with iron, folic acid, and other micronutrients in settings

where these foods are major staples

Prevent and treat malaria in pregnant women as part of strategies to prevent and control anaemia

Ensure universal access to and use of insecticide treated nets National policy makers, health service providers, development partners

Provide preventive malaria treatment for pregnant women in areas with moderate to National policy makers, health service providers

high malaria transmission

\section{Offer a healthy diet to all populations}

Create coherence in national policies and investment plans, including trade, food, Regional and national policy makers, food and beverage industries, creative and and agricultural policies, to promote a healthy diet and protect public health18*

media industries

Encourage consumer demand for healthy foods and meals*

\section{Promote physical activity in adolescents}

Create a conducive environment that promotes physical activity to tackle sedentary Regional, national, and local policy makers, urban planners, early years education, lifestyle ${ }^{19}+$ health services

\section{Promote optimal nutrition in adolescents with HIV/AIDS}

Provide nutrition counselling to improve health outcomes in adolescents with HIV ${ }^{20} \neq$ Health service providers, development partners

All recommended actions are based on those proposed in the Framework for Action issued by the Second International Conference on Nutrition in November 2014 except (*), which is based on a WHO healthy diet fact sheet; $(+)$, which is based on WHO guidelines on physical activity; and ( $)$, for which evidence is available but no formal WHO recommendation.

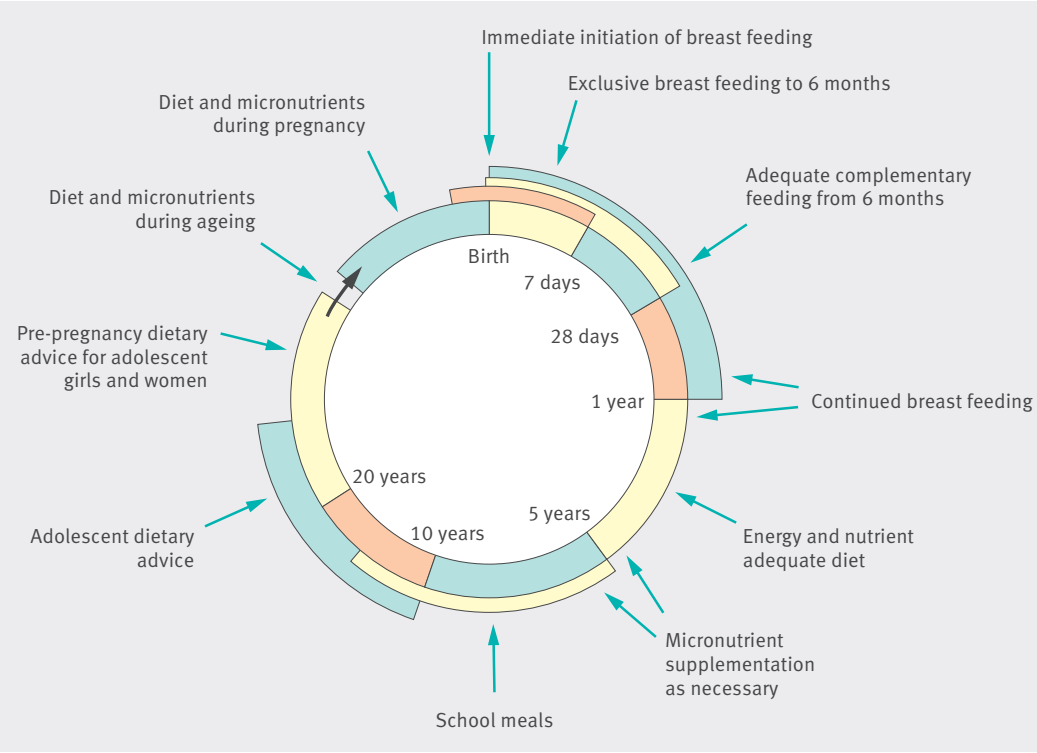

Fig 2 | Improving nutrition throughout the life course ${ }^{15}$
Specific recommendations and actions to help put them into practice are shown in tables 2 to 4.

\section{Actions to improve adolescent girls' nutrition}

Adolescent girls should be at the heart of a life course approach-a young adolescent girl is still a child, but often she will soon become a mother. Adolescent pregnancy is associated with higher risk of maternal mortality and morbidity, stillbirths, neonatal deaths, preterm births, and low birth weight. In addition to actions to prevent adolescent pregnancy and encourage pregnancy spacing, efforts are required to ensure that pregnant and lactating teenage mothers are adequately nourished.

Actions to improve child nutrition The first 1000 days of life (from pregnancy to the child's second birthday) present an 


\author{
Table 3 | Recommended actions to improve child nutrition \\ Recommendations and recommended concrete actions Who needs to take action? \\ Promote optimal infant and young child feeding* \\ Adapt and implement the International Code of Marketing of Breast Milk Substitutes National policy makers \\ and subsequent relevant World Health Assembly resolutions \\ Ensure that health services and employment policies promote, protect, and support National policy makers, employers, health facilities \\ breast feeding, including WHO's Baby-Friendly Hospital Initiative \\ Encourage and promote active participation of men in sharing care for infants and National policy makers, educational institutions, employers, health facilities \\ young children \\ Empower women and enhance their health and nutritional status throughout the life National policy makers, educational institutions, employers, health facilities \\ course \\ Ensure that policies and practices in emergency situations and humanitarian crises International organisations, national policy makers, humanitarian actors \\ promote, protect, and support breast feeding \\ Tackle maternal exposure to the availability and marketing of complementary foods International organisations, national policy makers, humanitarian actors \\ Improve supplementary feeding programmes for infants and young children International organisations, national policy makers, humanitarian actors \\ Improve coverage of treatment for wasting \\ Adopt policies and actions and mobilise funding to improve coverage using the \\ National policy makers, development partners, humanitarian actors, health services \\ community based management of acute malnutrition approach \\ Improve the integrated management of childhood illnesses National policy makers, health services \\ Reduce the risk of anaemia in children \\ Provide iron supplementation for pre-school children \\ National policy makers, health services \\ Reduce prevalence and severity of infectious disease in children \\ Provide zinc supplementation to reduce the duration and severity of diarrhoea and National policy makers, health services \\ to prevent subsequent episodes in children \\ Implement policies and programmes to ensure universal access to and use of $\quad$ National policy makers, health services \\ insecticide treated nets \\ Provide periodic deworming for all school age children in endemic areas \\ National policy makers, health services, schools \\ Improve the management of moderate acute malnutrition in children \\ Provide supplementary foods for the management of moderate acute malnutrition National policy makers, health services, development partners, humanitarian actors \\ in childrent \\ Reduce children's intakes of free sugars and sodium \\ Regulate the marketing of food and non-alcoholic beverages to children in \\ accordance with WHO recommendations \\ Provide adequate food in school settings

Promote physical activity in children \\ Create a conducive environment that promotes physical activity and tackles \\ sedentary lifestyle \\ heath and local \\ *Exclusive breast feeding up to age 6 months, followed by adequate complementary feeding (from 6 to 24 months) and continued breast feeding up to 2 years of age or beyond \\ All recommended actions are based on those proposed in the Framework for Action issued by the Second International Conference on Nutrition in November 2014 except ( + ), which is based \\ on a WHO Technical Note (www.who.int/nutrition/publications/moderate_malnutrition/9789241504423/en/).
}

important window of opportunity to improve child nutrition. The key pillar of any strategy to improve this-in addition to good maternal nutrition and health-is optimal feeding and care for infants and young children. Exclusive breast feeding (defined as the practice of giving an infant only breast milk for the first six months of life, with no other food or water), in particular, has the single largest potential effect on child mortality of any preventive intervention. Timely and adequate complementary feeding, with particular attention to vitamin and mineral content and the nutrient density of foods, is urgently needed.

\section{Actions to improve women's nutrition}

The health and nutrition statuses of women and children are intimately linked. Improving the health of women and children, therefore, begins with ensuring the health and nutritional status of women throughout all stages of life, and it continues with women being providers for their children and families. Thus, a key priority is female empowerment and women's full and equal access to, and control over, social protection and resources such as income, land, water, and technology. Direct multisectoral actions to tackle critical women's nutritional challenges, such as iron deficiency anaemia, need to be rolled out on a larger scale to achieve universal coverage.

Improving nutrition across the life course These targeted recommendations must be supported by a raft of nutrition interventions throughout the life course (see the ICN2 Framework for Action for the full range of recommended actions). Policies are needed, for example, to transform food systems and strengthen health systems. Universal access to functioning and resilient health systems and the scaled-up delivery of interventions can improve nutrition. Governments and international organisations also have a role in developing clear guidelines on healthy diets.

\section{What needs to happen now?}

If we want to improve the health of women, children, and adolescents, action to invest in nutrition is needed now. We know what needs to be done-as explained by the recommended actions in tables 2 to 4 -and the clear global commitments to action.

We now need to implement these commitments and ensure the resources to do so (the Addis Ababa Action Agenda refers to the need to scale up efforts to end hunger and malnutrition at paragraph 13 and the need to strengthen national health systems at paragraph 77). ${ }^{16}$ In a nutshell, actions are needed to improve the quality of diets; protect, promote, and support breast feeding; ensure that everyone has access to essential nutrition actions; provide adequate water and sanitation; and provide information and education.

To achieve these aims governments and society must join forces and make nutrition a priority. Governments, health services, the food and agriculture industries, schools and universities, and community leaders-along with many others-must work together in a coordinated and coherent way.

The potential human, societal, and economic gains from turning these commitments into action are substantial, and the costs of 
Table 4 | Recommended actions to improve women's nutrition

Recommended actions and evidence Who needs to take action?

Prevent and control anaemia

Promote consumption of nutrient dense foods, especially foods rich in iron $\quad$ National policy makers, food and agriculture sectors

Implement actions to ensure that pregnant and lactating adolescent mothers are National policy makers, development partners, food and agriculture sectors adequately nourished

Introduce measures to prevent adolescent pregnancy and to encourage pregnancy National policy makers, health service providers

spacing

Reduce the risk of low birth weight, maternal anaemia, and iron deficiency

Provide daily iron and folic acid and other micronutrient supplementation to National policy makers, health service providers

pregnant women as part of antenatal care

Provide intermittent iron and folic acid supplementation to menstruating women National policy makers, health service providers

where prevalence of anaemia is $20 \%$ or higher

Provide periodic treatment with anthelminthic (deworming) medicines for all National policy makers, health service providers, development partners

women of childbearing age living in endemic areas

Promote healthy weight gain and adequate nutrition during pregnancy

Provide dietary counselling to women during pregnancy

Prevent and treat malaria as part of anaemia prevention and control

Ensure universal access to and use of insecticide treated nets National policy makers, health service providers, development partners

Provide preventive malaria treatment for pregnant women in areas with moderate to National policy makers, health service providers, development partners high malaria transmission

\section{Ensure access to reproductive healthcare}

Ensure that women have comprehensive information about safe pregnancy and

delivery

Ensure that women have access to integral healthcare services that ensure

National policy makers, health service providers, development partners

adequate support for safe pregnancy and delivery

Promote protection of working mothers to support or sustain breast feeding

Implement policies and practices to promote protection of working mothers (eg, longer maternity leave, breaks to feed or express breast milk)

\section{Improve pregnancy outcomes for undernourished pregnant women}

To prevent pre-eclampsia, provide calcium supplementation for pregnant women in National policy makers, health service providers, development partners areas where dietary calcium intake is low and for higher risk women ${ }^{21 *}$

All recommended actions are based on those proposed in the Framework for Action issued by the Second International Conference on Nutrition in November 2014 except $(*)$,which is based on a WHO recommendation.

inaction are high. The time is right to tackle malnutrition in all forms at all ages and to break its intergenerational cycle.

The authors thank Karen McColl, Lina Mahy, Rebecca Olson, and Shelly Sundberg for their contributions to this paper. Competing interests: We have read and understood BMJ's policy on declaration of interests and have no relevant interests to declare.

The authors alone are responsible for the views expressed in this article, which does not necessarily represent the views, decisions, or policies of WHO or the institutions with which the authors are affiliated. Provenance and peer review: Not commissioned; externally peer reviewed.

Francesco Branca, director ${ }^{1}$

Ellen Piwoz, senior program officer ${ }^{2}$

Werner Schultink, chief of nutrition ${ }^{3}$

Lucy Martinez Sullivan, executive director ${ }^{4}$

${ }^{1}$ Department of Nutrition for Health and Development, World Health Organization, Avenue Appia 20, 1211 Geneva 27, Switzerland

2Bill and Melinda Gates Foundation, USA

3Unicef, New York, USA

${ }^{4} 1000$ Days, Washington, DC, USA

Correspondence to: FBranca brancaf@who.int

(c) World Health Organization 2015. Licensee BMJ This is an open access article distributed under the terms of the Creative Commons Attribution-

Noncommercial IGO License (https://creativecommons. org/licenses/by-nc/3.0/igo/), which permits use, distribution, and reproduction for non-commercial purposes in any medium, provided the original work is properly cited. In any reproduction of this article there should not be any suggestion that WHO or this article endorse any specific organisation or products. The use of the WHO logo is not permitted. This notice should be preserved along with the article's original URL.
Second International Conference on Nutrition. Conference outcome document: framework for action. Oct 2014. www.fao.org/3/a-mm215e.pdf. Second International Conference on Nutrition. Information note on the framework for action. 4 Nov 2014. www.fao.org/fileadmin/user_upload/faoweb/ ICN2/documents/InfoNote-e.pdf.

3 World Health Organization. WHA global nutrition targets 2025: stunting policy brief. 2014. www.who. int/nutrition/topics/globaltargets_stunting_ policybrief.pdf.

4 World Health Organization. WHA global nutrition targets 2025: wasting policy brief. 2014. www.who. int/nutrition/topics/globaltargets wasting policybrief.pdf.

5 Black RE, Victora CG, Walker SP, et al; Maternal and Child Nutrition Study Group. Maternal and child undernutrition and overweight in low income and middle income countries Lancet 2013:382:427-51.

6 Lim SS, Vos T, Flaxman AD, et al. A comparative risk assessment of burden of disease and injury attributable to 67 risk factors and risk factor clusters in 21 regions, 1990-2010: a systematic analysis for the Global Burden of Disease Study 2010. Lancet 2012;380;2224-60. International Bank for Reconstruction and Development, World Bank. Repositioning nutrition as central to development: a strategy for large scale action. 2006. https://openknowledge.worldbank.org/ handle/10986/7409.

8 World Health Organization. Comprehensive implementation plan on maternal, infant and young child nutrition. 2014. http://apps.who.int/iris/ bitstream/10665/113048/1/WHO_NMH_NHD_14.1 eng.pdf?ua $=1$.

9 Hoddinott J, Alderman H, Behrman JR, Haddad L, Horton $\mathrm{S}$. The economic rationale for investing in stunting reduction. GCC Working Paper Series 2013:13-08.

10 Hoddinott J, Horton S. Stunting as a sustainable development goal. SCN News 2015;41:59. www.unscn. org/files/Publications/SCN_News/SCNNEWS41_web_ low_res.pdf.

11 United Nations Secretary General. Global strategy for women's and children's health. Sept 2010. www.who. int/pmnch/topics/maternal/20100914_gswch_en.pdf.
12 Second International Conference on Nutrition. Conference outcome document: Rome declaration on nutrition. Oct 2014. www.fao.org/3/a-ml542e.pdf.

13 World Health Organization. Global nutrition targets 2025: childhood overweight policy brief (WHO/NMH/ NHD/14.6). 2014. www.who.int/nutrition/topics/ globaltargets_overweight_policybrief.pdf.

14 United Nations. The millennium development goals report 2014. 2014. www.un.org/ millenniumgoals/2014\%20MDG\%20report/MDG\%20 2014\%20English\%20web.pdf.

15 World Health Organization. Essential nutrition actions improving maternal, newborn, infant and young child health and nutrition. 2013. http://apps.who.int/iris/ bitstream/10665/84409/1/9789241505550_eng.pd

16 United Nations. The Addis Ababa action agenda of the Third International Conference on Financing for Development. July 2015. www.un.org/esa/ffd/ffd3/ wp-content/uploads/sites/2/2015/07/Addis-AbabaAction-Agenda-Draft-Outcome-Document-7-July-2015 pdf.

17 International Food Policy Research Institute. Global nutrition report 2014: actions and accountability to accelerate the world's progress on nutrition. 2014. http:// cdm15738.contentdm.oclc.org/utils/getfile/collection/ p15738coll2/id/128484/filename/128695.pdf.

18 World Health Organization. Healthy diet. Fact sheet no 394. May 2015. www.who.int/mediacentre/factsheets/ fs394/en/

19 World Health Organization. Global recommendations on physical activity for health. 2010. www.who.int/ dietphysicalactivity/publications/9789241599979/ en/.

20 World Health Organization. Nutrition counselling for adolescents and adults with HIV/AIDS. WHO e-Library of Evidence for Nutrition Actions (eLENA). July 2015. www.who.int/elena/titles/nutrition_hiv/en/.

21 World Health Organization. Guideline: calcium supplementation in pregnant women. 2013. www.who int/nutrition/publications/micronutrients/guidelines/ calcium_supplementation/en/.

Cite this as: $B M J$ 2015;351:h4173 